\title{
Creep-Feed Grinding: An Overview of Kinematics, Parameters and Effects on Process Efficiency
}

\author{
Sergey N. Grigoriev ${ }^{1}$ - Victor K. Starkov ${ }^{1}{ }^{*}$ - Nikolay A. Gorin ${ }^{1}$ - Peter Krajnik ${ }^{2}$ - Janez Kopač 2 \\ ${ }^{1}$ Moscow State University of Technology "Stankin", Russian Federation \\ ${ }^{2}$ University of Ljubljana, Faculty of Mechanical Engineering, Slovenia
}

Grinding kinematics is one of the main mechanisms affecting the behaviour and efficiency of the creep-feed grinding process; it is thus essential in understanding the interplay of its parameters in the material removal. This paper presents an overview of non-traditional process parameters, such as the apparent area of the removed material, the grinding force engagement angle, the ratio of normal-to-tangential grinding force, as well as the ratio between the depth of cut and the wheel diameter. The kinematic aspects of creep-feed grinding processes are illustrated in three different case studies for creep-feed grinding of turbine blades, gears and broaches, using highly porous, vitrified, alumina-oxide wheels at low speeds. Details about the experimental work, especially with regard to analysis and validation, are not included. Based on the case studies, however, some practical guidelines for improving process efficiency in terms of productivity and quality are provided.

Keywords: grinding, creep-feed, conventional, kinematics, parameters

\section{INTRODUCTION}

High-performance grinding, particularly in the automotive and aerospace industries, requires enhanced processes that provide increased efficiency with respect to productivity, quality and costs [1]. High wheel speeds are usually employed in the pursuit of high-performance grinding, because such speeds enable utilizing larger depths of cut and hence achieve higher material removal rates, leading to increased productivity [1] without compromising quality. The different applications of grinding employing large depths of cut include (a) creep-feed grinding for extremely deep forms, and (b) high-efficiency deep grinding (HEDG) for extremely high removal rates and deep forms [2]. Creep-feed grinding has been used as early as high-speed grinding, dating back to mid-1960s. In creep-feed grinding, low workpiece speeds and large depths of cut are used. Typical creep-feed workpiece speeds are lower than $60 \mathrm{~mm} /$ min [3]. In the early 1990s, however, HEDG emerged as a process that increased the efficiency of creepfeed grinding by using both higher wheel speeds and higher workpiece speeds. Tawakoli has shown that setting these two parameters at a unusually high level allows the realisation of high material removal rates and reduced grinding temperatures [4].

This paper presents an overview of three different applications of creep-feed grinding using highlyporous grinding wheels. In these case studies, the workpiece form is ground with large depths of cut, often even in a single grinding pass at the depth that can reach 10 or more millimetres, using workpiece speeds ranging from 40 to $500 \mathrm{~mm} / \mathrm{min}$, depending on the wheel speed, type of material being ground and surface integrity requirements [5]. Even though the major increase of creep-feed grinding efficiency has been driven by HEDG and by high-performance grinding machines, it is possible to increase the efficiency of creep-feed grinding even at wheel speeds that are sometimes as low as 20 to $35 \mathrm{~m} / \mathrm{s}$ [6]. This is an essential realization, since not all end-users in the industry have the possibility of utilizing HEDG due to its high costs.

Creep-feed grinding requires efficient cooling, achieved by providing a useful flow of the coolant to the grinding zone in order to convect heat and to avoid thermal damage [7]. Fluid flow through the grinding zone can be enhanced by the use of porous grinding wheels. It has been shown that creep-feed grinding with porous aluminium oxide wheels can yield extremely low energy partitions (fraction of heat entering the workpiece) of only 3 to $7 \%$, which are comparable to grinding applications with vitrified and electroplated CBN wheels [7]. This allows the material removal rate to be increased, since a highly porous grinding wheel generates less heat than a closed wheel; therefore, the amount of heat entering the workpiece is reduced. In this consideration, the highly-porous conventional grinding wheels are not obsolete and can be used for numerous creep-feed grinding applications. These wheels are also relatively inexpensive in comparison to CBN wheels and, therefore, are more cost efficient. The case studies included in this paper show satisfactory performance of these wheels with an open structure (ranging from 16 to 24). Special consideration is needed, however, because open structures means less bond, which can 
lead to excessive wear, in overly aggressive grinding conditions [6].

The behaviour of creep-feed grinding processes is defined mostly by its kinematics, which depend on the set of selected process parameters and the wheel topography. The set parameters further determine the thermal aspects of the process (e.g. heat flux, energy partition, grinding temperature) and a number of process outputs, such as a grit contact time, grinding forces, wheel wear, etc. Creep-feed grinding differs from conventional, shallow-cut grinding, particularly with respect to thermal aspects. The mechanics of chip removal, ground surface generation, along with quality outputs, e.g. thermal damage to the workpiece surface and sub-structural layer are given in [5] and [6]. These investigations, carried-out in Russia, highlight some unique parameters of creepfeed grinding. For example, different analytical approaches were applied to explain why it is possible to grind efficiently at the two extremes of material removal rate without excessive thermal damage in the intermediate depth-of-cut range; one such approach to analyse creep-feed grinding has been to characterize the angle of inclination of the contact plane [8].

Nevertheless, there is a need to introduce additional parameters of creep-feed grinding, not only for process analysis but also to identify the levers to increase process efficiency. More than 50 years have passed since the development of the first kinematic models of grinding processes; there are now numerous basic models available for process analysis, e.g. grinding wheel topography, chip thickness, grinding forces, energy, and temperature, etc. [9] and [10]. Interestingly, a different set of basic models evolved in Russian grinding research, resulting in parameters that are practically unknown internationally. This unknown theoretical base, suitable for creep-feed grinding analysis, is hence described in this paper, along with straightforward interpretations to aid in the improving of process efficiency. More specifically, the paper introduces parameters, including (a) the apparent area of removed material, (b) the grinding force engagement angle, (c) the ratio of normal to tangential grinding force, and (d) the ratio between the depth of cut and wheel diameter, which are useful in setting-up the grinding system. For example, the combination of wheel diameter and depth of cut can be optimised in order to minimize the ratio of normal to tangential grinding force. Furthermore, different interpretations of kinematics and guidelines for increasing process efficiency are given in order to increase the usefulness of the presented work, especially with respect to practicing engineers.
Three case studies are given to illustrate the ranges of process parameters for different applications. One case study is in the gas turbine industry: grinding a shank and an attachment section of a turbine blade. The other two examples refer to gear grinding and the grinding of broaching tools. Note that the ambition of this paper is not to experimentally verify or analyse any of these applications in any particular detail, but to revisit the grinding kinematics in view of largely unknown parameters and to simulate the effects on grinding efficiency by different selections of these parameters.

\section{KINEMATICS OF CREEP-FEED GRINDING}

In grinding, the kinematic relations between the wheel and the workpiece are typically analysed on the abrasive grit-cutting edge scale. The first analytical investigations of this type were made by Peklenik [11], who suggested that a limited number of kinematic cutting edges are actively engaged in material removal. Since then, numerous analyses of grinding kinematics, arising from consideration of the kinematic interactions between the grit and the workpiece, have been translated to the basic models of grinding wheel topography and chip thickness [9] and [10]. These basic models include parameters of grinding kinematics, such as the speed ratio (ratio between the wheel and the workpiece speed), as well as parameters of grinding geometry (e.g. depth of cut, equivalent wheel diameter) and parameters to quantify the topography (e.g. static density of the cutting edges) of the wheel surface [1]. However, kinematics can also be modelled on the macro scale [12].

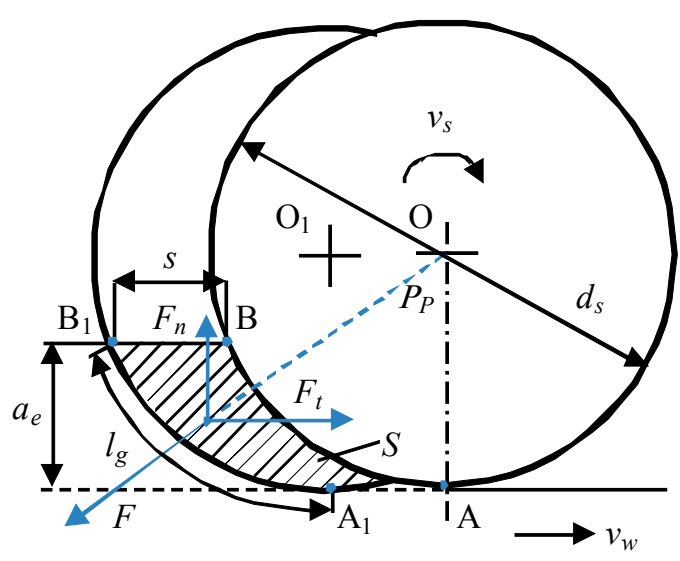

Fig. 1. Illustration of surface (straight) grinding

For surface (straight) grinding operation, shown in Fig. 1, commonly used for creep-feed grinding, the 
three main process parameters are (1) the wheel speed vs, (2) the workpiece speed vw, and (3) the depth of cut ae. The illustrated geometry corresponds to an up-grinding type of operation, in which the tangential directions of the wheel and workpiece motion are opposite. A cutting point in up-grinding begins its contact with the workpiece between Points A and A1 and ends at B1. The previous cutting point follows the same geometrical path shape but is displaced along the workpiece surface by the distance BB1, that corresponds to the feed-per-cutting point $\mathrm{s}$, which is equal to the product of the workpiece speed and the time between successive cuts [13].

Penetration of the grinding wheel into the workpiece results in the apparent area of removed material S, which can be expressed as:

$$
S=l_{g} \cdot s=\frac{v_{w}}{v_{s}} \cdot a_{e} \cdot d_{s}
$$

Here, $d_{s}$ is the wheel diameter and $l_{g}$ the arc length $\mathrm{AB}=\mathrm{A}_{1} \mathrm{~B}_{1}$ of the cutting path as the wheel centre moves from $\mathrm{O}$ to $\mathrm{O}_{1}$, and the grit passes through the contact zone. The area $S$ is inversely proportional to the speed ratio $v_{s} / v_{w}$ and is increased with the rise in both the wheel diameter $d_{s}$ and the depth of cut $a_{e}$. The geometric contact length, $l_{g}$, disregarding the contribution of feed per cutting edge, can be expressed as [2]:

$$
l_{g}=\sqrt{a_{e} \cdot d_{s}} .
$$

The grit contact time $\tau$ with the workpiece within the contact length (the contact time experienced by a grit during which Point $A$ of the grinding wheel moves to Point $\mathrm{B}_{1}$ ) is given by the geometric contact length $l_{g}$ divided by the wheel speed $v_{s}$ :

$$
\tau=\frac{l_{g}}{v_{s}} .
$$

Simultaneously, within the same contact time, the grit moves horizontally, as governed by the feed-percutting point $s$, limiting the apparent area of material removal by $\mathrm{BB}_{1}=\mathrm{AA}_{1}$, whereas the geometric contact length limits the same area by $A B=A_{1} B_{1}$. Note that the wheel and grit deflection effects are not taken into account.

The total force vector $F$ generally increases with the apparent area of removed material $S$ and, among others, depends on grinding geometry and kinematics. The other influencing factors on the magnitude of $F$ are: (1) mechanical properties of workpiece material (e.g. strength and hardness); (2) chip thickness; (3) wear-flat area (due to wear and dressing); and (4) contact conditions between the grit and the workpiece (i.e. contact stress and friction coefficient). The direction of vector $F$ is determined by the grinding force engagement angle $\alpha_{P}$, calculated as:

$$
\alpha_{P}=\frac{l_{g}}{2} \cdot \frac{4}{\pi d_{s}} \cdot 90^{\circ}=57.32 \cdot \sqrt{\frac{a_{e}}{d_{s}}} .
$$

Typical $\alpha_{P}$ values for creep-feed grinding lie in the range between 1.8 to 12 degrees [6].

An additional parameter of the grinding kinematics is the cotangent of the grinding force engagement angle $\alpha_{P}$, which is the ratio of normal grinding force $F_{n}$ to tangential grinding force $F_{t}$ :

$$
\frac{F_{n}}{F_{t}}=\operatorname{ctg} \alpha_{P} .
$$

Note that this parameter is the inverse of the more commonly used grinding force ratio, indicating the relationship of tangential force relative to the normal force [2]. Weal wear is not considered in the presented analysis of grinding kinematics; however, it should be mentioned that as the wheel wear progresses, the tangential force increases slightly, but the normal force increase is more drastic.

\section{INTERPRETATION OF CREEP-FEED GRINDING KINEMATICS}

Grit contact time as a grain passes through the contact length $\tau$ is an parameter in process analysis, particularly in consideration of grinding temperatures [2]. Typical $\tau$ values for grinding processes range between $10^{-3}$ to $10^{-5}$ seconds (larger values for creepfeed grinding). In consideration of the fact that the time $\tau$ is remarkably short, we can treat the determined kinematic parameters as instantaneous, which should be applied for the analysis of the process.

As mentioned earlier, it is possible to determine the number of kinematic cutting edges in contact with the workpiece per unit area [11]. The number of active cutting edges involved in material removal is proportional to the number of kinematic cutting edges. In conventional shallow-cut grinding with an 80 -grit 12-structure aluminium oxide wheel (diameter $d_{s}=500 \mathrm{~mm}$ ), approximately 3.3 abrasive grits can theoretically be in contact with the workpiece over the contact length of $1 \mathrm{~mm}$ during the grit contact time of $\tau$ [6]. In contrast, for a creep-feed grinding scenario using the same wheel and cutting depths in the range between 0.5 to $10 \mathrm{~mm}$, a much larger number of grits, 
i.e. 50 to 200 , could be actively engaged in material removal within the contact length between 15.8 to 70.7 $\mathrm{mm}[6]$. In general, the number of kinematic cutting edges increases with the depth of cut. Moreover, the number of kinematic cutting edges increases with the workpiece speed and decreases with both the wheel speed and the wheel diameter [14]. Considering only the larger depths of cut (characteristic for creep-feed grinding), the associated higher number of kinematic cutting edges leads to a higher concentration of active cutting edges lying close to each other, which can cause high temperatures in the grinding zone and, hence, a risk of thermal damage in case a temperature equilibrium is established. However, this is not the case in creep-feed grinding. According to Malkin and Guo [5], creep-feed grinding with relatively fast workpiece speeds is characterized by the inclined heat source (tending in a direction from $A$ to $B_{1}$ in Fig. 1) associated with the large depth of cut. This leads to a situation where some heated material in the wedge ahead of the grinding zone is removed with the chips during the grinding process, thereby resulting in lower temperatures on the finished ground surface (area $\mathrm{AA}_{1}$ in Fig. 1). Similar observations have been made by others, who investigated the phenomena experimentally [4], [8], [14] and [15].

The grinding force engagement angle $\alpha_{P}$ (Eq. (4)) increases with the depth of cut (while in contrast the $F_{n} / F_{t}$ value declines), and decreases when utilizing grinding wheels with larger diameters. The latter interrelation is somewhat ambiguous, because grinding with a large wheel diameter generally yields large contact lengths. Therefore, it is necessary to investigate the $a_{e} / d_{s}$ ratio, i.e. the ratio between the depth of cut and the wheel diameter, in greater detail. An increase in the $a_{e} / d_{s}$ ratio causes the vector $F$ to slightly move from the normal OA, towards the machined surface, to line $\mathrm{BB}_{1}$ parallel to it (straight surface of the workpiece). For example, if the depth of cut increases from $a_{e}=1$ to $10 \mathrm{~mm}$, the grinding force engagement angle increases from $\alpha_{P}=2.56$ to 8.11 degrees, or by the factor of 3.17. Simultaneously, the ratio between the normal and tangential grinding force, $F_{n} / F_{t}$, is decreased from 22.3 to 7 . Note, however, that the $F_{n} / F_{t}$ ratio also depends on the dressing conditions, the wheel sharpness and the penetration depth of the grit, and not solely on the grinding geometry. For example, a dull wheel would have a larger $F_{n} / F_{t}$ ratio without any change in the grinding geometry. Nevertheless, these factors are not considered in the interpretation of grinding kinematics in focus here.
Additional interpretations can be made into grinding kinematics. The illustrated wheel engagement in creep-feed grinding, shown in Fig. 1 , suggests that the limit of theoretical depth of cut is $a_{e}=d_{s} / 2$. Correspondingly, the upper limits for the grinding force engagement angle $\alpha_{P}$ lie between 40.53 to 57.32 degrees in case of $a_{e} / d_{s}=0.5$. Running the process at such extremes would be advantageous from the viewpoint of grinding kinematics and attainable material removal rates, but impossible to implement in practice due to mechanical limitations in machine tools and grinding wheels. In more realistic, commonly applied grinding scenarios, the $a_{e} / d_{s}$ ratios for conventional shallow-cut grinding are between $10^{-6}$ and $10^{-4}$; ratios corresponding to the grinding force engagement angle $\alpha_{P}$ in the range between 0.1 to 1.2 degrees. The applications of creep-feed grinding using conventional wheels typically employ $a_{e} / d_{s}$ ratios of $10^{-3}$ to $10^{-2}$, and the grinding force engagement angle $\alpha_{P}$ in the 1.8 to 12 degrees range. These typical values of $a_{e} / d_{s}$ and $\alpha_{P}$ can be used as criteria for determining whether the application refers to a creep-feed grinding operation. Finally, it should be noted that the $a_{e} / d_{s}$ ratio is not related to wheel and workpiece speeds or, therefore, to the machining time. The ratio only refers to the grinding force engagement angle $\alpha_{P}$ and the ratio of normal to tangential grinding force $F_{n} / F_{t}$.

\section{ILLUSTRATIVE CASE STUDIES}

The kinematics of creep-feed grinding is illustrated in three different case studies related to grinding of (1) turbine blades, (2) gears and (3) broaches. The ranges of kinematic parameters used for comparison are presented in Table 1.

Table 1. Ranges of kinematic parameters [6]

\begin{tabular}{lccc}
\hline Process & $(1)$ & $(2)$ & $(3)$ \\
\hline$d_{s}[\mathrm{~mm}]$ & 500 & 300 & 100 \\
\hline$a_{e}[\mathrm{~mm}]$ & 0.5 to 10 & 0.1 to 6 & 0.002 to 0.2 \\
\hline$V_{W}[\mathrm{~mm} / \mathrm{min}]$ & 90 to 400 & 200 to 2000 & 300 to 10000 \\
\hline$V_{s}[\mathrm{~m} / \mathrm{s}]$ & 28 to 30 & 35 & 25 \\
\hline$Q_{W}^{\prime}\left[\mathrm{mm}^{3} /(\mathrm{mm} \cdot \mathrm{s})\right]$ & 3.3 to 14.9 & 2.5 to 20 & 0.33 to 1 \\
\hline$a_{e} / d_{s}$ & $10^{-3}$ to $2 \cdot 10^{-2}$ & $3 \cdot 10^{-4}$ to $2 \cdot 10^{-2}$ & $2 \cdot 10^{-5}$ to $2 \cdot 10^{-3}$ \\
\hline$S\left[\mathrm{~mm}^{2}\right]$ & 0.034 to 0.15 & 0.021 to 0.206 & 0.0033 to 0.011 \\
\hline$\alpha_{p}\left[{ }^{\circ}\right]$ & 1.81 to 8.11 & 1.05 to 8.11 & 0.26 to 2.56 \\
\hline$F_{n} / F_{t}$ & 7.01 to 31.53 & 7.01 to 54.56 & 23.31 to 214.9 \\
\hline$a g g r$ & 7 to 30 & 10 to 25 & 9 to 30 \\
\hline
\end{tabular}

Considering that the introduced parameters are neither widely known nor widely used in the analysis of grinding kinematics, it is useful to make a 
comparison to a more standard parameter used in the industry today, in particularly to the aggressiveness number, aggr, introduced by Badger [15]. This nondimensional parameter is a simplification of the maximum chip thickness model and can be calculated as:

$$
a g g r=10^{6}\left(\frac{v_{w}}{v_{s}}\right)\left(\frac{a_{e}}{d_{e}}\right)^{1 / 2} .
$$

\subsection{Creep-Feed Grinding of Turbine Blades}

Turbine blades made of nickel-base alloys can be ground using conventional wheels. The use of CBN grinding wheels, which have high thermal conductivity, is generally the preferred approach to grinding this type of material; nevertheless, the expense of grinding is high in such cases. Therefore, a conventional aluminium-oxide wheel, e.g. vitrified 80-grit, F-grade, 16-structure, 25A wheel (diameter $500 \mathrm{~mm}$, width $25 \mathrm{~mm}$ ) can be used for profiling of turbine blades. Wheels of this type are soft with an extremely open structure (high-porosity) that reduce the tendency for dulling. The grinding of the blade shank and the attachment section was done simultaneously using a profiled wheel, as shown in Fig. 2. Additional contours of the blade, the Z-profile, platforms, and blade roots were also ground [6].

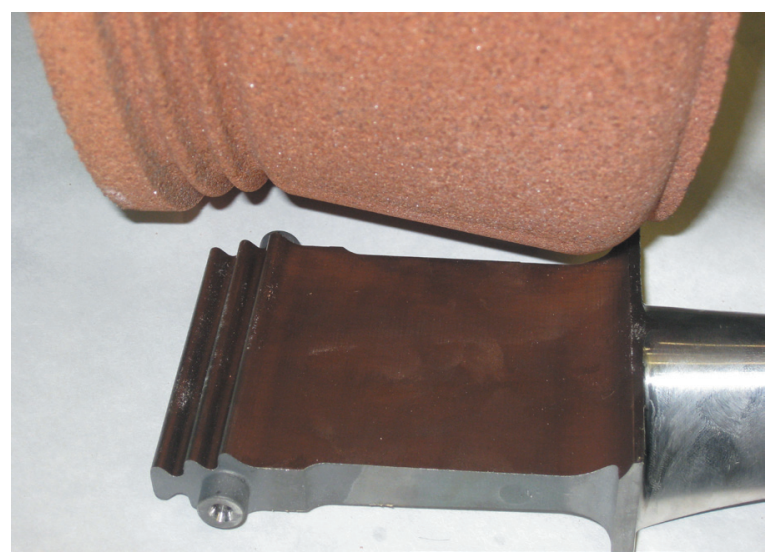

Fig. 2. Grinding of turbine blades

The apparent area of removed material $S$ depends on the depth of cut, and ranges from 0.068 to 0.293 $\mathrm{mm}^{2}$ when the depth of cut is increased by a factor of 20. The $a_{e}=10 \mathrm{~mm}$ depth of cut gives a specific material removal rate of $Q^{\prime}{ }_{w}=14.9 \mathrm{~mm}^{3} /(\mathrm{mm} \cdot \mathrm{s})$, which is large for conventional wheels. The grinding force engagement angle $\alpha_{P}$ increases proportionally with the depth of cut and ranges between 1.81 to 8.11 degrees. Simultaneously, the $F_{n} / F_{t}$ ratio between the normal and tangential grinding force is decreased from 31.53 to 7.01 .

Due to large depths of cut, ranging from 0.5 to $10 \mathrm{~mm}$, the geometric contact lengths are also great, enabling enhanced cooling at the grinding zone; effective cooling is crucial for creep-feed grinding with highly porous wheels in order to avoid thermal damage. A 3.5\% concentration emulsion was applied for cooling with a pressure of 12 bar and a flow rate of $200 \mathrm{l} / \mathrm{min}$.

Material investigations (not given here) showed an undamaged surface layer, with no noticeable metallographic changes in the microstructure, and with compressive residual stresses on the ground surface [6]. The improved efficiency refers to a reduction of the number of grinding passes that leads to fewer cycles of heating. This, combined with lower grinding temperatures, are the main advantages of creep-feed grinding in terms of thermal damage.

\subsection{Creep-Feed Grinding of Gears}

Another example of creep-feed grinding refers to profiling of gear tooth flanks, shown in Fig. 3. Here, the grinding wheel machines a single flank in the direction of grinding per tooth gap. This process allows grinding of different moduli with an unchanged wheel width.

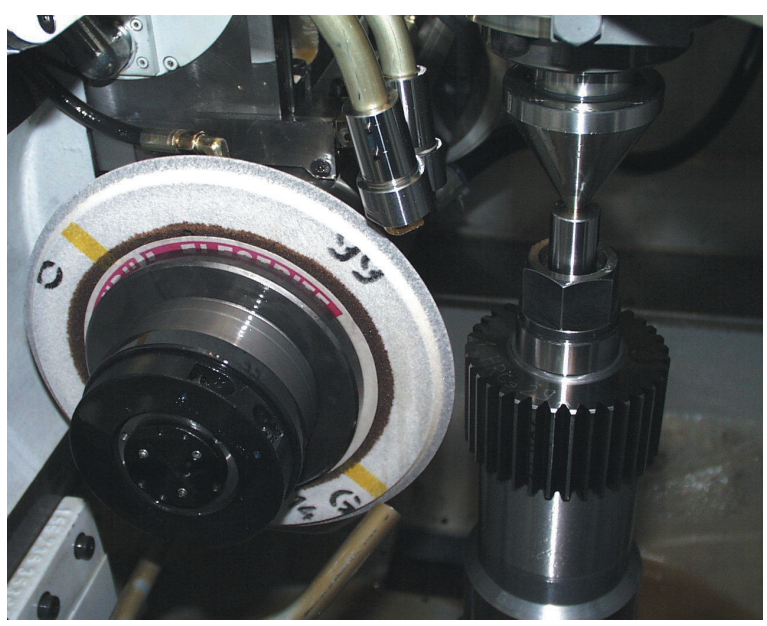

Fig. 3. Profiling of a gear

Typical gears to be ground have moduli of 1 to $6 \mathrm{~mm}, 5$ to 130 teeth, widths between 5 to $70 \mathrm{~mm}$, and diameters of 50 to $600 \mathrm{~mm}$. Grinding of gears normally requires several grinding passes. The maximal depth of cut for the first grinding pass depends on the gear module. For example, creep-feed grinding of a gear with a module between 3 to $5 \mathrm{~mm}$ 
enables employment of depths of cut ranging from 6 to $10 \mathrm{~mm}$ when using 300 to $350 \mathrm{~mm}$ wheels [6]. In terms of productivity, conventional grinding of gears yields Q'w between 2.5 to $20 \mathrm{~mm}^{3} /(\mathrm{mm} \cdot \mathrm{s})$, which is associated with 0.017 to $0.033 a_{e} / d_{s}$ ratios.

For this application, a typical wheel could be an 80-grit, G-grade, 14-structure, 25A aluminium oxide wheel (diameter $300 \mathrm{~mm}$, width $20 \mathrm{~mm}$ ). Again, this is a soft conventional wheel with very open structure, offering better grinding economics in comparison to CBN [6].

For further illustrating an industrial use of this process, two different process variants are discussed in [7]: (1) grinding with two passes, with $6 \mathrm{~mm}$ depth of cut for the first pass and $0.75 \mathrm{~mm}$ for the second pass; (2) grinding with five passes ranging from the maximum depth of cut of $2.4 \mathrm{~mm}$ for the first pass down to $0.1 \mathrm{~mm}$ in the last pass. The tested depths of cut were hence varied between 0.1 to $6 \mathrm{~mm}$ as further detailed in Table 1. In this case, we have the apparent area of removed material $S$ ranging between 0.021 to $0.172 \mathrm{~mm}^{2}$. The grinding force engagement angle $\alpha_{P}$ increases simultaneously from 1.05 to 8.11 degrees. The first grinding variant with two grinding passes is more efficient than the second variant comprised of five grinding passes. Moreover, the overall decrease in the ratio between the normal and tangential grinding force $F_{n} / F_{t}$ from 54.56 to 7.01 gave a sharp cut resulting in sufficient grinding quality.

\subsection{Creep-Feed Grinding of Broaches}

The last case study of creep-feed grinding is a broaching tool application, shown in Fig. 4.

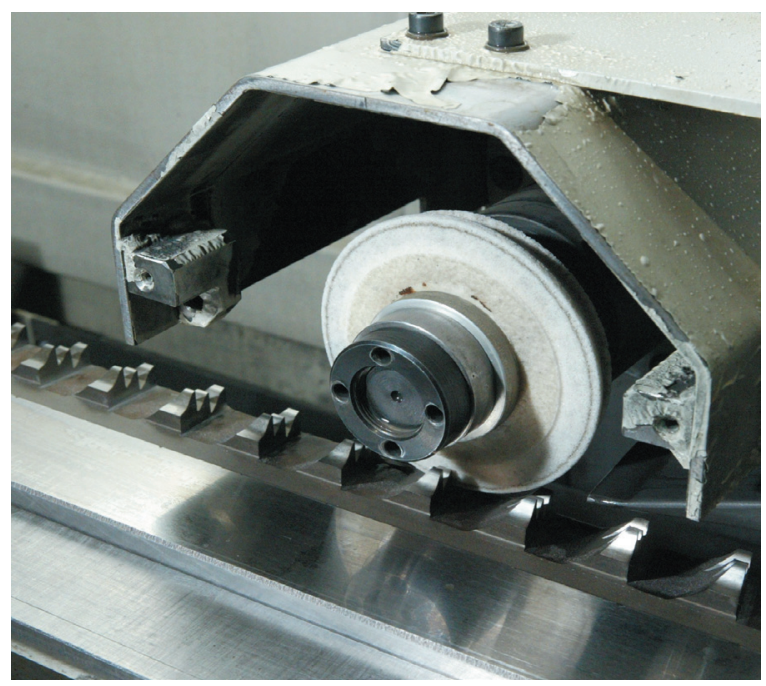

Fig. 4. Grinding of a broaching tool
Broaching is used to produce internal slots, such as dovetails and turbine disk roots using a large broaching machine. Turbine disk broaches are large and can contain hundreds of cutting edges to produce the slots. The high cost and maintenance of such tools makes grinding appropriate not only for producing the tools but also the remanufacturing (retrofitting) of them.

In a conventional broach grinding scenario, for example, a profiled, vitrified 80-grit, H-grade, 12-structure, 25A aluminium oxide wheel (diameter $100 \mathrm{~mm}$, width $30 \mathrm{~mm}$ ) can be used. This wheel is not as soft and opened as the other two wheels exemplified in this section. Nevertheless, the wheel still features an open structure and is soft; characteristics that are required for grinding of hardened steel (e.g. hardness of broaches is between 61 to $68 \mathrm{HRC}$ ).

Grinding depths employed in this case study are not as large as in the previous examples. The depths range from 0.002 to $0.2 \mathrm{~mm}$, giving a specific material removal rate up to $Q^{\prime} w=1.67 \mathrm{~mm}^{3} /(\mathrm{mm} \cdot \mathrm{s})$. This process uses a small wheel diameter and is considered as creep-feed grinding operation because the ae/ds ratio is greater than $10^{-3}$ to $10^{-2}$, according to Starkov [6]. The grinding force engagement angle $\alpha_{P}$ increases proportionally with the grinding depth from 0.26 to 2.56 degrees. At the same time, the $F_{n} / F_{t}$ ratio is decreased non-proportionally, from 214.9 to 23.31 .

\subsection{Guidelines for Improving Creep-Feed Grinding Process Efficiency}

The high temperatures in grinding can cause various types of thermal damage, affecting the integrity of a ground surface. The threshold for the onset of thermal damage largely depends on the material being ground. For example, high temperature nickelbase alloy tolerates grinding temperatures up to $1200{ }^{\circ} \mathrm{C}$. For grinding of hardened steels, however, the temperature reached at the grinding zone should not exceed $723{ }^{\circ} \mathrm{C}$ (critical temperature of steel) to avoid detrimental metallurgical transformations. As a practical matter, it is therefore desirable to be able to quantify grinding temperature associated with metallurgical transformations that occur during creepfeed grinding. For this, temperature measurements by a thermocouple using a semi-dynamic method were carried out [6]. It was found experimentally that the increase of grinding depth makes the grinding temperature to rise sharply, and then, at the depth of 0.1 to $0.15 \mathrm{~mm}$, the temperature rises more slowly, and, finally, becomes stable at the depth of $0.2 \mathrm{~mm}$ [16]. In this case, the grinding temperature remained 
constant during an increase of the depth of cut, i.e. from 0.2 to $0.5 \mathrm{~mm}$, where the ae/ds ratio value equalled $6.7 \cdot 10^{-4}$. The temperature reached at the grinding zone became stable, meaning that higher ae/ ds ratios created advantageous conditions for both material removal and thermal aspects of the process [6]. Based on this reference example, it is possible to assume that the major guideline to enhance grinding efficiency in terms of avoiding thermal damage is to change the ae/ds ratio (for a given process kinematics and wheel topography). When this ratio is enlarged on account of increasing the depth of cut, ae, and, if possible, decreasing the grinding wheel diameter ds, suitable preconditions are created for grinding with higher grinding force engagement angles $\alpha \mathrm{p}$. In this scenario, the vector of applied cutting force shifts in the direction of removed material and more heat is evacuated from the grinding zone with chips.

Fig. 5 shows the variation of the three discussed kinematic parameters when the depth of cut is increased from 0.5 to $10 \mathrm{~mm}$, which corresponds to the $a_{e} / d_{s}$ ratio in the range between 0.001 and 0.02 .

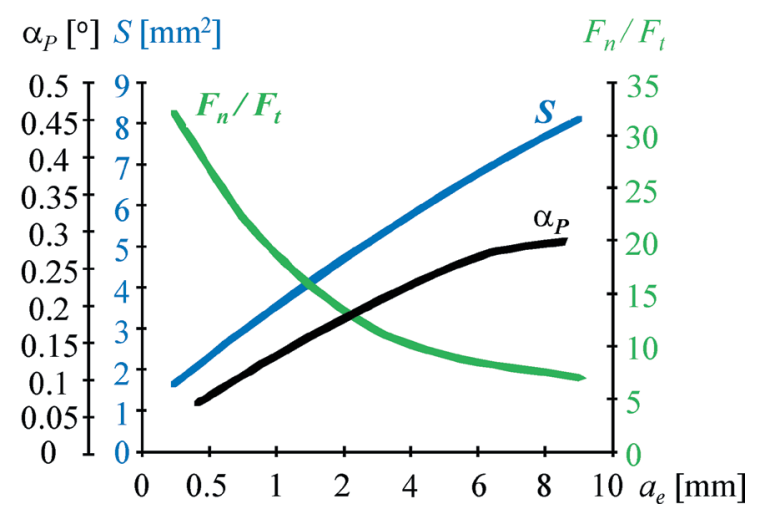

Fig. 5. Variation of kinematic parameters with the depth of cut

The variations shown are characteristic for the grinding of turbine blades using a wheel with a $d_{s}=$ $500 \mathrm{~mm}$ diameter and an $a_{e}=10 \mathrm{~mm}$ depth of cut, and the grinding of gears using a wheel with a diameter of $d_{s}=300 \mathrm{~mm}$ and a depth of cut $a_{e}=6 \mathrm{~mm}$. Here, the $a_{e} / d_{s}$ ratio equals 0.02 for both cases, meaning that the processes have the same $\alpha_{p}$ and $F_{n} / F_{t}$ values. Nevertheless, during the creep-feed grinding of blades, the apparent area of removed material $S$ is 1.7 times higher in comparison with creep-feed grinding of gears, even though the workpiece speed $v_{w}$ was 2.2 times lower ( 90 vs. $200 \mathrm{~mm} / \mathrm{min}$ ). The apparent area of removed material is proportional to workpiece speed $v_{w}$, wheel diameter $d_{s}$ and depth of cut $a_{e}$, whereas the grinding force engagement angle $\alpha_{p}$ decreases with larger wheel diameters. A compromise can be achieved by simultaneously minimizing $a_{e} /$ $d_{s}$ and $d_{s} \cdot a_{e}$ values. In practice, wheels with smaller diameters should be used while keeping the $a_{e} / d_{s}$ ratio fixed. In this way, the creep-feed grinding efficiency can be improved, so that the benefits (e.g. low energy partitions [17] and avoiding of thermal damage) are achieved with lower depths of cut. The effect of wheel diameter $d_{s}$ (for different depths of cut $a_{e}$ ) on grinding force engagement angle $\alpha_{p}$ is shown in Fig. 6.

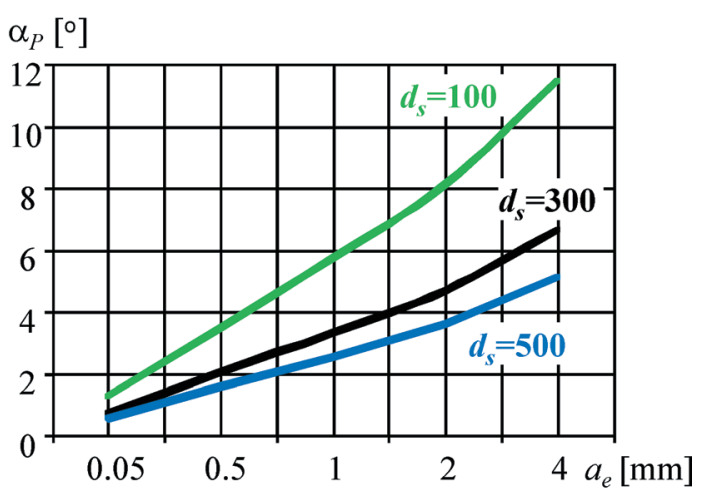

Fig. 6. Effect of wheel diameter ds on $\alpha_{p}$

As mentioned earlier, characteristic $\alpha_{\mathrm{P}}$ values for creep-feed grinding are between 1.8 to 12 degrees. Based on the figure above, it is apparent that creepfeed grinding conditions are achieved earlier using smaller wheels. More specifically, the grinding wheel with $d_{s}=100 \mathrm{~mm}$ diameter, achieves kinematic conditions for creep-feed grinding at the cutting depth of $a_{e}=0.0986 \mathrm{~mm}$. Similarly, grinding with a $d_{s}=300$ $\mathrm{mm}$ wheel, requires a depth of cut of $a_{e}=0.296 \mathrm{~mm}$, while during grinding using the wheel with $d_{s}=500$ $\mathrm{mm}$, creep-feed grinding conditions are reached at $a_{e}=0.493 \mathrm{~mm}$.

The workpiece speed $\mathrm{vw}$ is another key parameter for improving process efficiency, because it significantly affects the material removal rate (productivity) and the heat transfer into the workpiece, which are quantities reliant on the apparent area of removed material $S$. At the same time, higher workpiece speeds aid in more heat remaining in the path of the advancing $\mathrm{S}$ with less time for it to be conducted into the workpiece, which in turn leads to a reduction of the grinding temperature. In so doing, it is practical to use higher workpiece speeds in both creep-feed grinding and shallow-cut grinding with lower depths of cut. 


\section{CONCLUSIONS}

This paper overviews the non-traditional parameters (reflecting different understanding of the functional potentials of basic grinding models) for characterizing the kinematics of creep-feed grinding and investigating their effects on process efficiency. Kinematics has been derived and analysed using parameters, such as apparent area of removed material $S$, grinding force engagement angle $\alpha_{P}$, ratio of normal to tangential grinding force $F_{n} / F_{t}$, as well as the ratio between the depth of cut and the wheel diameter ae/ $d_{s}$. These parameters evolved over many years in Russian grinding research and are largely unknown internationally. The useful ranges of parameters are presented in illustrative examples of creep-feed grinding of turbine blades, gears and broaches. These case studies suggest that process efficiency can be increased when using highly-porous aluminium-oxide wheels run at low speeds. The benefits of creep-feed grinding, such as increased material removal rate and reduced risk of thermal damage (grinding burn), can be achieved, e.g. once the values of grinding force engagement angle are in the 1.8 to 12 degrees range.

It has been shown that the work-piece speed is the key parameter for improving process efficiency. Furthermore, when grinding with a particular wheel diameter, the depth of cut should increase in order to maximize the grinding force engagement angle while minimizing the ratio of normal to tangential grinding force. The interpretation of grinding kinematics suggests that grinding with smaller wheel diameters is beneficial, because creep-feed grinding benefits can be achieved at lower depths of cut. The introduced parameters can thus be used to select the proper combination of wheel diameters and grinding parameters for different process applications.

\section{REFERENCES}

[1] Kopac, J., Krajnik, P. (2006). High-performance grinding - a review. Journal of Materials Processing Technology, vol. 175, p. 278-284, DOI:10.1016/j. jmatprotec.2005.04.010.

[2] Rowe, W.B. (2009). Principles of Modern Grinding Technology. William Andrew Publishing, Norwich.

[3] Andrew, C., Howes, T.D., Pearce, T.R. (1985). Creep Feed Grinding. Holt, Rinehart \& Winston, Eastbourne.

[4] Tawakoli, T. (1993). High Efficiency Deep Grinding. VDI-Verlag and Mechanical Engineering Publications, London.

[5] Malkin, S., Guo, C. (2007). Thermal analysis of grinding. Annals of the CIRP - Manufacturing
Technology, vol. 56, no. 2, p. 760-782, DOI:10.1016/j. cirp.2007.10.005.

[6] Starkov, V.K. (2007). Shlifovanie vysokoporistymi krugami [Grinding with highly porous grinding wheels]. Mashinostroenie, Moscow. (in Russian)

[7] Starkov, V.K., Ryabtsev, S.A., Gorin, N.A. (2012). Povyshenie effektivnosti protsessov glubinnogo shlifovaniya [Efficiency improvement in deep grinding processes]. Moscow State University of Technology "Stankin", Moscow. (in Russian)

[8] Peklenik, J. (1957). Ermittlung von geometrischen und physikalischen Kenngrößen für die Grundlagenforschung des Schleifens [Determination of geometrical and physical parameters for basic grinding research]. Doctoral Thesis, TH Aachen, Aachen.

[9] Rowe, W.B. (2001). Thermal analysis of high efficiency deep grinding. International Journal of Machine Tools and Manufacture, vol. 41, no. 1, p. 1-19, DOI:10.1016/ S0890-6955(00)00074-2.

[10] Tönshoff, H.K., Peters, J., Inasaki, I., Paul, T. (1992). Modelling and simulation of grinding processes. Annals of the CIRP - Manufacturing Technology, vol. 41, no. 2, p. 677-688, DOI:10.1016/S0007-8506(07)63254-5.

[11] Brinksmeier, E., Aurich, J.C., Govekar, E., Heinzel, C., Hoffmeister, H.-W., Klocke, F., Peters, J., Rentsch, R., Stephenson, D. J., Uhlmann, E., Weinert, K., Wittmann, M. (2006). Advances in modeling and simulation of grinding processes. Annals of the CIRP-Manufacturing Technology, vol. 55, no. 2, p. 667-696, DOI:10.1016/j. cirp.2006.10.003.

[12] Drazumeric, R., Krajnik, P., Vrabic, R., Meyer, B., Butala, P., Kosel, F., Kopac, J. (2010). Modelling of grinding gap macro geometry and workpiece kinematics in throughfeed centreless grinding. Journal of Materials Processing Technology, vol. 210, no. 1, p. 104-109, DOI:10.1016/j.jmatprotec.2009.08.006.

[13] Malkin, S., Guo, C. (2008). Grinding Technology: Theory and Applications of Machining with Abrasives, $2^{\text {nd }}$ ed. Industrial Press, New York.

[14] Klocke, F., König, W. (2005). Fertigungsverfahren 2: Schleifen, Honen, Läppen [Manufacturing Processes 2: Grinding, Honing, Lapping]. $4^{\text {th }}$ ed. Springer Verlag, Berlin, Heidelberg.

[15] Badger, J. (2009). Factors affecting wheel collapse in grinding. Annals of the CIRP - Manufacturing Technology, vol. 58, no. 1, p. 307-310, DOI:10.1016/j. cirp.2009.03.048.

[16] Silin S.S., Hrulkov, V.A., Lobanov, A.V., Rykunov, N.S. (1984). Glubinnoe shlifovanie detalei iz trudnoobrabatyvaemykh materialov [Deep grinding of difficult-to-machine materials]. Mashinostroenie, Moscow. (in Russian)

[17] Jin, T., Stephenson, D.J. (2003). Investigation of the heat partitioning in high efficiency deep grinding. International Journal of Machine Tools and Manufacture, vol. 43, no. 11, p. 1129-1134, DOI:10.1016/S0890-6955(03)00123-8. 